(b) re-orientation of occupational therapy services away from rehabilitation and towards improvement in quality of life

(c) expansion of the roles of social workers to improve social skills among residents and monitor quality of life indices

(d) expansion in the role of community mental health nurses as case managers

(e) improvement in communication with hospitals in the preparation of discharge plans

(f) investigation of the outcome for residents who leave the hostel system

(g) a study of ways to improve compliance with medication.

\section{References}

Buchan, T. \& SMITH, R. (1989) Nursing process in community psychiatric nursing. Australian Journal of Advanced Nursing, 6, 5-11.

Howat, J. G. M. \& KoNTNY, E. L. (1982) The outcome for discharged Nottingham long-stay in-patients. British Journal of Psychiatry, 141, 590-594.

LAMB, R. (1970) The new asylums in the community. Archives of General Psychiatry, 36, 129-134.

- \& GOERTZEL, V. (1971) Discharged mental patients are they really in the community? Archives of General Psychiatry, 24, 29-34.

Weisbrod, B. A., Test, M. A. \& Stein, L. I. (1980) Alternatives to mental hospital treatment II. Economic benefit - cost analysis. Archives of General Psychiatry, 37, 400-405.

\title{
New mental health legislation in Japan
}

\section{Tsutomu Sakuta, Chief of Out-patient Psychiatric Clinic, Keio University Hospital, and Deputy Secretary General, International Council of Prison Medical Services, Keio University, 35 Shinano-machi, Shinjuku-ku, Tokyo 160, Japan}

In Japan the Mentally Disordered Persons Supervision and Protection Law (1901) and the Mental Hospital Law (1919) used to be the main laws for mentally disordered people. Subsequently, the Mental Hygiene Law came into force in 1950 but was criticised as it had restrained admitted patients and the provisions for procedures for the release of patients were inadequate. The purpose of the old law was to give medical treatment and custody to mentally disordered persons and to maintain and improve the mental health of the nation. In the revised law, enacted in July 1988, acceleration of social rehabilitation of mentally disordered persons and promotion of their well-being were added.

The conflict between the legal model, intended to restrict legally the right of discretion of physicians, and the medical model has become active in various countries. From about 1965 there was an international trend emphasising the legal model in the revision of the Mental Hygiene Law which also affected revision of the law in Japan. The Mental Health Law of Japan was established by incorporating the legal model into the medical model and can be described as follows:

\section{General provisions}

\section{Purpose of the Law}

The name of the law was changed from the Mental Hygiene Law to the Mental Health Law, "the purpose of this law is to provide mentally disordered persons, etc. with medical care and custody, as well as to promote their social rehabilitation, and to make efforts toward the prevention of mental disorders, and the maintenance and improvement of the mental health of other people, in an attempt to advance the general well-being of mentally disordered persons, etc. and to improve the mental health of the nation".

\section{Duties of the National, Prefectural and Local} Governments

It is stated that "the National, Prefectural and Local Governments shall endeavour to enable mentally 
disordered persons to adapt themselves socially by expanding and improving the facilities needed for medical care, social rehabilitation and other welfare purposes and education, and shall take measures necessary for the prevention of mental disorders and the improvement of the mental health of the nation, by promoting surveys and research on mental health, disseminating knowledge on mental health, etc".

As to Duties of the Nation, "the nation shall endeavour to maintain and improve the collective mental health, to deepen its understanding of mentally disordered persons and to cooperate with the efforts of those suffering from mental disorders, etc. in overcoming their problems and endeavouring toward social rehabilitation".

\section{Definition of the mentally disordered person}

This is the same in the revised law as the one used in the Mental Hygiene Law which leaves problems to be solved in the future. A "mentally disordered person" refers to a psychotic person (including those who are psychotic due to intoxication), a mentally retarded person, or a psychopathic person.

\section{Admission for medical care}

This can be classified into:

(a) Voluntary admission

This is based on the consent of the patient in person and is defined as the basic form of admission for mental hospitals. When a voluntarily admitted mentally disordered person requests discharge, a designated physician of mental health can refrain from discharging him for a period of not longer than 72 hours if the physician deems it necessary to continue the admission.

(b) Admission for medical care and custody When a person who has been deemed by the superintendent of a mental hospital, as a result of the medical examination of a designated physician, to be mentally disordered, and to be in need of admission to a hospital for medical care and custody, and when a person responsible for his custody has consented to the admission, the superintendent may admit him to the hospital without his consent. This form of admission is not found in Europe and the US.

(c) Involuntary admission by the Prefectural Governor

This is forced admission carried out for a mentally disordered person liable to injure himself or others because of his mental disorder. The decision must be made by two designated physicians who must report on the person's condition periodically. (d) Emergency admission

If the superintendent of a mental hospital designated by a Prefectural Governor, as one in compliance with the criteria specified by the Minister of Health and Welfare, has been required to take urgent action with regard to a person for whom the superintendent has been requested to provide medical care and custody, he may admit the person concerned to a hospital for a period of not longer than 72 hours, without his/her consent, after the superintendent has concluded, as a result of the medical examination conducted by a Designated Physician, that the person in question is mentally disordered, and there would be extreme interference with his medical care and custody unless he is admitted to the hospital without delay. Any mental hospital which admits such mentally disordered people must be designated as an emergency mental hospital by a Prefectural Governor; public mental hospitals have mainly been so designated. The requirements for such mental hospitals are availability of highly advanced techniques of investigation and medical care.

(e) Temporary admission If a guardian, a spouse, a person who exercises parental power, or any other person responsible for the support of a person who has been suspected by the superintendent of a mental hospital, as a result of the medical examination conducted by a Designated Physician, to be mentally disordered, and to require a reasonably long time for his diagnosis, has agreed on his admission, the superintendent may admit him to the hospital for no longer than three weeks without his voluntary consent.

(f) General admission

This form of admission is the same as for admissions due to diseases of internal medicine. Admissions of patients with neurosis fall into this category.

In cases of admission of mentally disordered persons, notice must be submitted to the concerned Prefectural Government for admissions for medical care and custody, emergency admissions, and temporary admissions. The condition of the admitted person must be reported to the concerned Prefectural Government (by way of the Director of the Public Health Centre of the Community) once every 12 months for admissions for medical care and custody, and once every six months for involuntary admissions, by the Prefectural Government. The notice of admissions and periodic 
reports received by a Prefectural Governor will be sent to the Psychiatric Review Board, which review cases and decide whether admission is needed. Results of the review will be notified to the concerned Prefectural Government.

\section{Designated Physician of Mental Health}

To protect the human rights of patients, it was decided to designate physicians who have more than a certain level of knowledge and skills of psychiatric care as Designated Physicians of Mental Health. For involuntary admissions by Prefectural Government, admissions for medical care and custody, and for confining actions of patients, diagnosis established by the Designated Physician is required.

A specialist in psychiatry can be requested to give a psychiatric judgement, while he cannot have any legal right to confine the freedom of a patient. However, some physicians of mental hospitals should have a role to confine freedom of individual mentally disordered persons. For this purpose, it is required to have designated physicians.

\section{Isolation and physical restraint}

The superintendent of a mental hospital may, with regard to a person admitted to the hospital, impose necessary restrictions on his actions within a limit indispensable to his medical care or custody but not impose restrictions on the sending and receiving of correspondence, meetings with the staff of a Prefectural Government or another administrative organ, and other restrictions specified by the Minister of Health and Welfare after listening to the opinions of the Public Health Council.

Only when a Designated Physician has deemed it necessary may restrictions on the actions of a patient, such as isolation and other restrictions, be imposed.
In this case, the Designated Physician shall record the matters specified by a Health and Welfare Ministerial Ordinance on the medical record without delay.

\section{The Local Mental Health Council and the Psychiatric Review Board}

Provisions for protection of human rights are as follows:

a duty to inform the patients of their rights by written notification

a system to review whether admission of a patient is adequate or not, based on the notices of admission and periodic reports

to submit requests for discharge by the patient himself or a guardian of the patient

the Psychiatric Review Board has been established in Prefectural Government

the inspection of mental hospitals by the Ministry

of Health and Welfare and the Governor of Prefectural Government has been established.

\section{Future tasks}

\section{Establishment of social rehabilitation facilities for} mentally disordered persons

Efforts have been made in many places in Japan to establish social rehabilitation facilities for mentally disordered persons. However, such facilities are not yet adequate and to run such facilities is economically difficult at present.

\section{Measures for cases difiicult to be handled}

Since in Japan there are no security units, such as those seen in foreign countries, it is yet to be determined what future measures should be taken for such difficult to handle cases. 